This item was submitted to Loughborough's Research Repository by the author.

Items in Figshare are protected by copyright, with all rights reserved, unless otherwise indicated.

\title{
Modelling deformation during the construction of wrapped geogrid reinforced structures
}

PLEASE CITE THE PUBLISHED VERSION

http://dx.doi.org/10.1680/jgein.15.00049

\section{PUBLISHER}

(c) Thomas Telford (ICE Publishing)

\section{VERSION}

NA (Not Applicable or Unknown)

\section{LICENCE}

CC BY-NC-ND 4.0

\section{REPOSITORY RECORD}

Scotland, lan, Neil Dixon, Matthew W. Frost, Gary John Fowmes, and G. Horgan. 2019. "Modelling Deformation During the Construction of Wrapped Geogrid Reinforced Structures". figshare. https://hdl.handle.net/2134/19815. 


\title{
Modelling deformation during the construction of wrapped geogrid-reinforced structures
}

\author{
I. Scotland ${ }^{1}$, N. Dixon ${ }^{2}$, M. Frost ${ }^{3}$, G. Fowmes ${ }^{4}$ and G. Horgan ${ }^{5}$ \\ ${ }^{1}$ Research Engineer, Centre for Innovative Construction Engineering, Loughborough University, UK, \\ Telephone: +44 1509 228549; Telefax: +44 1509 223980; E-mail: i.j.scotland@gmail.com \\ ${ }^{2}$ Professor, School of Civil and Building Engineering, Loughborough University, UK, \\ Telephone: +44 1509 222637; Telefax: +44 1509 223980; E-mail: n.dixon@lboro.ac.uk \\ (corresponding author) \\ ${ }^{3}$ Senior Lecturer, School of Civil and Building Engineering, Loughborough University, UK, \\ Telephone: +44 1509 222637; Telefax: +44 1509 223980; E-mail: m.w.frost@lboro.ac.uk \\ ${ }^{4}$ Lecturer, School of Civil and Building Engineering, Loughborough University, UK, \\ Telephone: +44 1509 222637; Telefax: +44 1509 223980; E-mail: g.j.fowmes@lboro.ac.uk \\ ${ }^{5}$ Managing Director, Huesker Limited, Warrington, UK, Telephone: +44 1925 629393; \\ Telefax: +44 1925 629394; E-mail: graham.horgan@huesker.co.uk
}

Received 30 March 2015, revised 02 July 2015, accepted 09 October 2015, published 11 January 2016

\begin{abstract}
Although geogrids and geotextiles have been successfully used for over a quarter of a century to reinforce soil, there are currently no commonly agreed analytical methods to model their deformation behaviour. The serviceability limit state is becoming an ever more important design consideration, as structures are built with increasingly tighter tolerances. Although there are many deformation databases and design charts available, providing information and guidance on the sensitivity to certain design variables, these are largely focused on facets such as height, shear strength and geogrid ultimate strength and do not consider construction method. Following a review of existing analytical and empirical guidance, this paper presents numerical modelling-derived guidance for flexible faced geogrid-reinforced structures constructed using cohesionless fill that incorporates installation methods. The modelling approach is validated against measured results from three varied case studies, before analysing the changes in deformation distribution resulting from two different construction methods (layer-by-layer and full height construction). For the conditions analysed, including height of the structure, the lateral deformation resulting from layer-by-layer construction, was shown to be consistently greater, than for full height construction. In contrast, an analysis of postconstruction deformation, for each of the construction methods, found full height construction to be more sensitive to post-construction loading, for the conditions considered. For low wall height structures constructed using the layer-by-layer method, $<5 \mathrm{~m}$, the present study indicates that horizontal face deformations are underestimated by current guidance.
\end{abstract}

KEYWORDS: Geosynthetics, Reinforced soil, Deformation, Serviceability limit state

REFERENCE: Scotland, I., Dixon, N., Frost, M., Fowmes, G. and Horgan, G. (2016). Modelling deformation during the construction of wrapped geogrid-reinforced structures. Geosynthetics International, 23, No. 3, 219-232. [http://dx.doi.org/10.1680/jgein.15.00049]

\section{INTRODUCTION}

Deformation in geogrid-reinforced structures (GRS) is becoming an ever more important design consideration, as structures are built with increasingly tighter tolerances. First geotextiles, from the 1980s, and later geogrids from the 1990s, offer major technical, sustainable and cost benefits to civil engineering (Raja et al. 2012; Stucki et al. 2011; WRAP 2010). Their design has been historically linked with that for metallic strips and anchors but their performance has routinely suggested they offer completely different performance (Allen and Bathurst 2002). As a result, new design methods are required that consider this composite effect. As a composite structure, combining the benefits of compressively strong soil and tensile-resistant polymer-based reinforcement, there are a large number of potential factors that can influence the deformation performance of GRS. These include, but are not limited to, geometrical properties such as structural height and reinforcement length, as well as the long-term creep characteristics of the polymeric reinforcement.

This paper reports on the definitions of deformation and typical ranges; gives a review of the existing analytical and empirical deformation guidance; explains the 


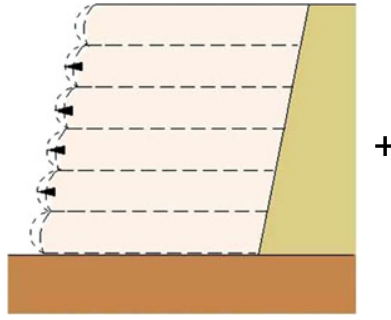

(a)

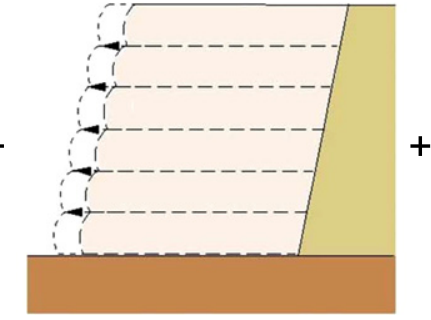

(b)

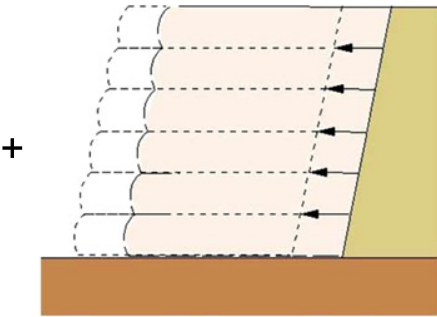

(c)

Figure 1. Horizontal deformation components in GRS: (a) face deformation; (b) internal deformation; (c) global GRS deformation

proposed numerical modelling procedure that can be used to include construction effects; and presents validation against a range of case studies; The numerical model is used to assess two methods of construction, using full height formwork and layer-by-layer formwork.

\section{DEFORMATION IN GEOGRID-REINFORCED STRUCTURES}

\subsection{General}

By their nature, GRS are flexible structures and as such they deform during their service life. This deformation can be defined as the action of changing shape and is typically measured relative to an outside point of reference. Typically GRS are considered as two-dimensional (2D) structures acting in plane strain where they are laterally constrained in the out-of-plane direction. These structures tend to deform outwards horizontally from the face as a result of geogrid strain, and vertically due to settlement, consolidation and vertical displacement caused by the aforementioned horizontal movement.

This paper focuses on horizontal deformation of GRS, which can be classified on the basis of where it occurs in relation to the structure (Figure 1), as listed here.

(1) Face deformation, occurring in wrapped faced GRS as bulging, resulting from straining of the facing elements under lateral earth pressure and vertical deformation.

(2) Internal GRS deformation, occurring within the body of the structure, primarily from straining reinforcement, under tensile load, or soil shearing.

(3) Global GRS displacement, occurring outside the region of reinforced soil and can result in the whole structure moving forward/sliding.

This paper focuses on deformation occurring within the reinforced body [(1) and (2)] and does not consider global deformation (3), assuming it can be considered by typical reinforced soil design. Distinction can be made between deformation occurring during and after the construction phase. Published data from three wrapped GRS case studies (Benjamim et al. 2007; Alexiew and Detert 2008; Ehrlich and Mirmoradi 2013) in which deformation was monitored during and after construction, indicate that the ratios of maximum construction to maximum post-construction deformation were $3: 1,4: 1$ and $7: 2$, respectively, showing that deformation during construction is the dominant period of internal deformation in GRS.

\subsection{Design and deformation}

In Europe the design of GRS is not covered by the Eurocode for geotechnical design, EN 1997 (BSI 2004). Instead, it remains the responsibility of individual states to recommend design documents, resulting in a plethora of design approaches with varying procedures, safety margins and philosophies. These include BS 8006:2010 (BSI 2010) in the United Kingdom, EBGEO (DGG 2011) in Germany, Nordic Guidelines for Reinforced Soils and Fills (NGG 2005) in Scandinavia, and NF P94-270 (AFN 2009) in France. Globally there are similar documents proposing design methods, such as the Design Manual for Segmental Retaining Walls (NCMA 2002), AASHTO (2012) in the United States and Geoguide 6 (Jones 2002) in Hong Kong, among others.

These mainly limit-equilibrium-based design methods have been shown to be overly conservative in determining realistic forces and deformations in GRS (Allen and Bathurst 2002; Bathurst et al. 2010). However, by considering additional factors such as toe embedment, reinforcement stiffness and compaction it is possible to achieve closer agreement (Ehrlich and Mirmoradi 2013; Ehrlich et al. 2012). Explicit serviceability limit state (SLS) design methodologies, considering deformation are not typically included within these design documents (Scotland et al. 2012). These methods have been adapted from theories for traditional retaining walls and do not consider the unique characteristics that the combination of soil and geogrid create, as highlighted in research by McGown and Yogarajah (1993), Bussert and Cavanaugh (2010) and Wu et al. (2013). In the absence of analytical models that can explain this composite effect designers typically use empirically derived charts and relationships as guidance. Some of the most popular of these deformation models are reviewed in Section 2.3.

\subsection{Existing deformation guidance}

There is a wide range of analytical and empirical deformation guidance available (Giroud et al. 1989; Jewell and Milligan 1989; Christopher 1993; Chew and Mitchell 1994; Wu 1994; Lee 2000; Wu et al. 2013; Allen and Bathurst 2015). These have been briefly summarised in Table 1. The most prominent of these is the ' $\mathrm{K}$-stiffness method', first presented by Allen et al. (2003) and later updated by Bathurst et al. (2008) and more recently by 
Table 1. Overview of existing empirical and analytical deformation guidance

\begin{tabular}{|c|c|c|c|c|c|}
\hline Reference & $\begin{array}{l}\text { Materials } \\
\text { covered }\end{array}$ & Validation data & Facing type & $\begin{array}{l}\text { Location of } \\
\text { deformation }\end{array}$ & Variables considered \\
\hline (1) Allen and Bathurst (2015) & Geogrid & Case studies/NM & Wrapped/segmental & Internal & $H / \Delta \sigma_{\mathrm{v}} / \varphi / c / E A / \varepsilon / \gamma / S_{\mathrm{v}}$ \\
\hline & Geotextile & & & & \\
\hline (2) Bathurst et al. (2002) & Geogrid & Case studies & Wrapped/segmental & Face & $H / \Delta \sigma_{\mathrm{v}}$ \\
\hline (3) Chew and Mitchell (1994) & Geotextile & NM/case studies & Segmental & Face & $H / L / E A / S_{\mathrm{v}} / \Delta \sigma_{\mathrm{v}}$ \\
\hline (4) Christopher (1993) & Geotextile & $\mathrm{NM} /$ case studies/centrifuge & Segmental & Face & $H / L / E A / S_{\mathrm{v}} / \varphi / c$ \\
\hline (5) Giroud et al. (1989) & $\begin{array}{l}\text { Geogrid } \\
\text { Geotextile }\end{array}$ & Analytical & None & Internal & $L / \varepsilon$ \\
\hline (6) Lee (2000) & Geotextile & NM/case studies & Wrapped/segmental & Internal & $H / E A / S_{\mathrm{v}}$ \\
\hline (7) Jewell and Milligan (1989) & Geotextile & Analytical & Wrapped & Face & $H / \varphi / \psi / \gamma / E A / S_{\mathrm{v}} / \Delta \sigma_{\mathrm{v}}$ \\
\hline (8) Wu (1994) & $\begin{array}{l}\text { Geogrid } \\
\text { Geotextile }\end{array}$ & Analytical & None & Internal & \\
\hline (9) Wu et al. (2013) & Geotextile & Analytical & Wrapped/segmental & Internal & $H / \varphi / \psi / \gamma / E A / S_{\mathrm{v}} / \Delta \sigma_{\mathrm{v}}$ \\
\hline
\end{tabular}

NM, numerical model.

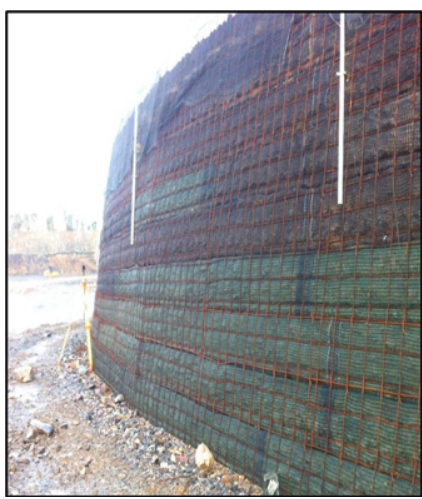

(a)

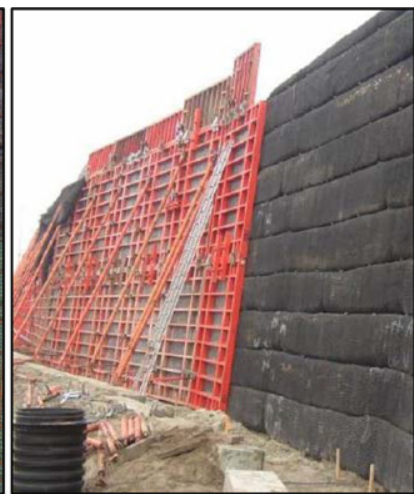

(b)

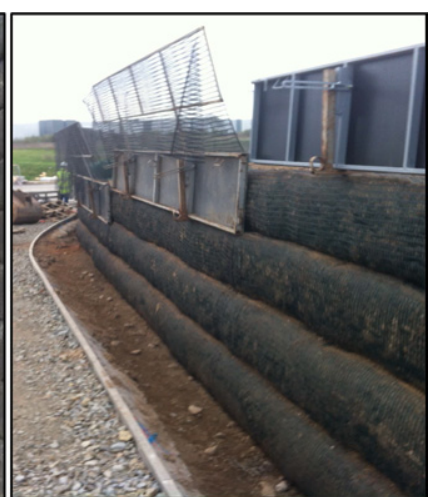

(c)

Figure 2. Construction methods for wrapped GRS: (a) permanent steel mesh formwork, (b) temporary full height formwork, (c) temporary layer-by-layer formwork

Allen and Bathurst (2015). It incorporates a number of empirically calibrated parameters that enable the calculation of maximum tension and strain deformation in each layer. These authors used a wide range of case studies and instrumented test walls to develop the method. The scope of the method covers wrapped and segmental block-faced walls, by applying a correction factor for wrapped or block-faced GRS. Bathurst et al. (2002) also present a supplementary height-normalised chart, displaying measured face deformation data for three instrumented case studies.

Christopher (1993) and Chew and Mitchell (1994) offer alternative deformation models in the form of charts. Both were originally based on block-faced, geotextile-reinforced structures and cover a wide range of parameters. However neither method accounts for flexibility of the face, which has been shown to play an important factor in contributing to deformation resistance (Bathurst et al. 2006).

Many of the leading deformation models consider similar variables, such as soil properties, geometry and reinforcement characteristics. The range of factors, displayed in Table 1, does not include compaction and construction techniques. As shown herein (Section 4), these can have a considerable effect on total deformation.

\subsection{Construction techniques}

\subsubsection{Overview}

One variable not yet included in GRS charts and design guidance is the construction method. Specifically, the construction of wrapped GRS requires some form of lateral restraint or propping, during backfilling and compaction. Typically, there are three general propping methods, which provide the lateral restraint required during placement and compaction of fill. These three are: permanent formwork (Figure 2a), temporary full height formwork (Figure 2b) or temporary layer-bylayer formwork (Figure 2c). Permanent formwork, typically in the form of segmental blocks or steel mesh is extensively covered (Christopher 1993; Chew and Mitchell 1994; Lee 2000; Bathurst et al. 2006; Mirmoradi and Ehrlich 2015b) and has therefore not been analysed in this study.

\subsubsection{Full height temporary formwork}

In this case, the GRS is constructed to its full height while laterally restrained behind a full height propped panel. This panel is then released in one action, allowing the structure to deform. 


\subsubsection{Layer-by-layer formwork}

Contrasting with full height construction, the structure is built behind localised facing panels, often covering a single layer. These are released locally after subsequent layers are constructed. This means that deformation occurs throughout the construction process. This form of construction is favoured in cases where a full height propping solution is not possible due to costs and construction feasibility.

\section{NUMERICAL MODELLING OF GRS}

\subsection{Previous numerical modelling}

Numerical modelling software has been successfully used in modelling GRS by many researchers (e.g. Hatami and Bathurst 2005; Guler et al. 2007; Alexiew and Detert 2008; Huang et al. 2009; Wu et al. 2013; Mirmoradi and Ehrlich 2015a; Yu et al. 2015) to investigate a range of parameters that influence behaviour. However none have considered more than one construction method and their effect on the magnitudes of deformation both during and after construction.

\subsection{Proposed numerical model}

\subsubsection{General}

This study used the 2D finite-element (FE) modelling code, PLAXIS 2D Anniversary Edition v.2 (2014), herein referred to as Plaxis 2D. It has previously been used by many different researchers (Guler et al. 2007; Alexiew and Detert 2008; Herold and Wolffersdorff 2009; Anubhav and Basudhar 2011; Ehrlich and Mirmoradi 2013; Damians et al. 2015; Mirmoradi and Ehrlich 2015a), and is commercially available and used in design practice.

Plaxis 2D is a FE program that has been specifically adapted for modelling geotechnical structures such as retaining walls, tunnels and embankments, in plane strain or axisymmetric conditions. The program features preprogrammed constitutive models for soil and geogrid, and allows staged construction, where clusters of finite elements are activated or deactivated to simulate a particular construction sequence.

\subsubsection{Soil model and input parameters}

The soil for each case study is modelled using a preprogrammed constitutive model called the 'Hardening Soil (HS) Model with Mohr-Coulomb Failure Criteria' (Schanz et al. 1999). Unlike a linear-elastic perfectly plastic model, the HS model is elasto-plastic, featuring a hyperbolic strain-stiffness relationship. It also includes compression hardening, to simulate the irreversible compaction of soil. It is defined by parameters: $E_{50}^{\mathrm{ref}}, E_{\mathrm{oed}}^{\mathrm{ref}}$, $E_{\text {ur }}^{\text {ref }}, p^{\text {ref }}, m$ which are the secant stiffness, oedometric stiffness, unloading-reloading stiffness, reference stress and a power factor, respectively.

More complex models, such as the 'Hardening Soil Model with Small Strain', that allow varied soil stiffness at small strain (below $0.1 \%$ ), but given typically strains in GRS range from 1 to $\%$ (Allen and Bathurst 2002), this was unnecessarily complex, as the later sensitivity analysis shows (Section 3.4).

Following Hatami and Bathurst (2005), the shear strength parameters: $\varphi$ and $c$, which represent friction angle and cohesion respectively, have been obtained from plane-strain tests. The dilation angle of the soil, $\psi$, has been taken to obey the relationship with friction angle, introduced by Bolton (1986). Although defined as a cohesionless soil, a small cohesion value, $<1.0 \mathrm{kN} / \mathrm{m}^{2}$, has been incorporated into each model to prevent the initial stress state from being on the tip of the yield surface. The impact of its inclusion is assessed in Section 3.4.

\subsubsection{Geogrid}

Geogrid is a complex planar material with insignificant thickness and non-linear stiffness. In the numerical model it has been simply modelled using a planar element with perfect elastic-plastic linear stiffness, defined by two parameters: combined area and elastic modulus, $E A$, averaged per metre width and can be obtained solely from tensile test data; as well as $N_{\mathrm{p}}$, representing the plastic threshold. In design, appropriate geogrid selection should ensure that this threshold is not reached, as this would lead to rupture failure (ultimate limit state).

Determination of $E A$ follows the principle of compatibility, as suggested by McGown and Yogarajah (1993), where soil strain and geogrid strain must be apportioned in selecting an appropriate secant modulus. Extensive sensitivity study of working strain levels in geogrid (Section 3.5), resulted in selecting a $2 \%$ secant stiffness modulus for each geogrid modelled, based on available tensile test data. The value selected for stiffness should be suitable to the time period considered in design, to account for the action of creep. The case studies included in this paper only consider polyester and polyvinyl alcohol geogrids, that under short-term $(<1$ year) working stress conditions feature approximately linear stiffness and do not exhibit strains greater than $2 \%$, partly due to high reduction and safety factors applied in their design process (Kaliakin et al. 2000; Allen and Bathurst 2002). The rheological behaviour of polymeric reinforcement is more pronounced under high strain levels where stiffness softening can occur. Therefore a detailed evaluation of creep and reducing stiffness with time is beyond the scope of this study.

\subsubsection{Geometry, boundary conditions and interfaces}

The geometry of each numerical model was created to within $0.1 \mathrm{~m}$ of each structure. The geometry of the models was restricted to the reinforced soil section only, to highlight deformation occurring internally and on the face of each structure. A fixed boundary condition in both the horizontal and vertical directions was modelled directly below the base of the GRS. The compressibility of weak foundation has been shown to influence facing deformation in GRS (Rowe and Skinner 2001); however, in this analysis all three case studies selected were founded on incompressible or firm ground. To restrict deformation to the reinforced section, a horizontal ( $x$-direction) constraint was added immediately at the back tip of the 
geogrids. Trial modelling of case studies 2 and 3 , including backfill and embedment, revealed no noticeable difference $(<5 \%)$ in deformation at the face.

The interface between soil and geogrid elements in each case was modelled rigidly with no reduction in interface strength (i.e. $R_{\text {inter }}=1.0$ ), as suggested for geogrids by Mirmoradi and Ehrlich (2015a). This follows the assumption that interface shear resistance is sufficient, so that geogrid pull-out or soil-geogrid sliding does not occur. This assumption is not valid for geotextile reinforcements which typically have lower soil-interface shear strength. Assuming rigid interfaces does not allow relative movement between the soil and geogrid interfaces, and therefore all numerical model examples need to be checked to ensure maximum stress levels are below the ultimate limit state of pull-out. This can be assessed using established design practices as discussed in Section 2.2.

\subsubsection{Construction method modelling}

The construction process was modelled using a staged construction procedure in which, after defining the boundaries, the structure was built in full layers defined by the geosynthetic vertical spacing, behind a horizontal restraint. Upon completion of each layer, compaction was modelled by applying a two-stage load-unload cycle of opposing vertical distributed loads above and below each layer, as shown in Figure 3. This method is based on the assumption by Ehrlich and Mitchell (1994), that each wrapped layer has been compacted in thin increments $(<0.3 \mathrm{~m})$ and that the compactive effort throughout the layer is equal, as shown by Mirmoradi and Ehrlich (2015a). This method does not take into account instances in which heavier compaction induces additional compactive effort in the lower layers, or where lighter compaction is achieved near the face.

Both full height and layer-by-layer construction methods were modelled using horizontal constraints on the wrapped face. These were deactivated, differently for both construction methods, to simulate the removal of formwork. In full height construction, they were all deactivated simultaneously upon reaching total height, whereas the restraint for each layer was deactivated after the in-filling of a subsequent layer.

\subsection{Validation of numerical method}

\subsubsection{Overview}

To validate the performance of the construction modelling method, three differing GRS were modelled using the FE program. Their calculated deformations were compared with the measured deformation behaviour assessed in the field.

\subsubsection{Case study 1: $0.8 \mathrm{~m}$ high model using full height construction method}

Deformation data from controlled laboratory tests was used to validate the numerical model. The $0.8 \mathrm{~m}$ high tests were undertaken at Loughborough University, UK, and consisted of two $0.4 \mathrm{~m}$ thick wrapped layers (Figure 4). They were constructed using uniformly sized sand, which was tested to have the properties displayed in Table 2.

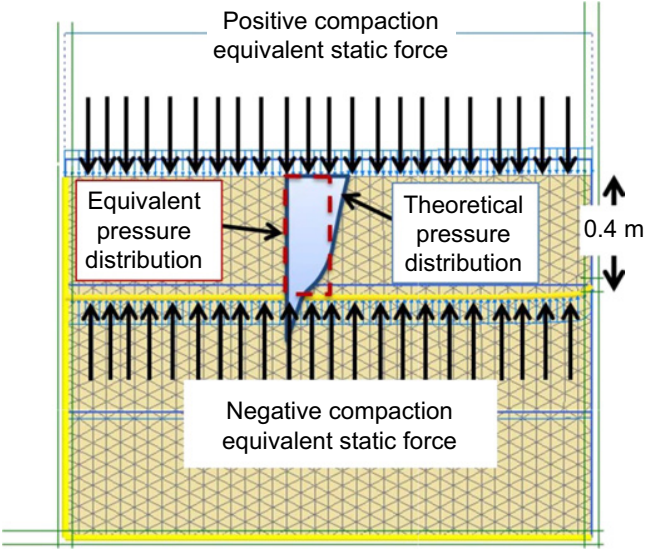

Figure 3. Compaction modelling in numerical model after Mirmoradi and Ehrlich (2015b)

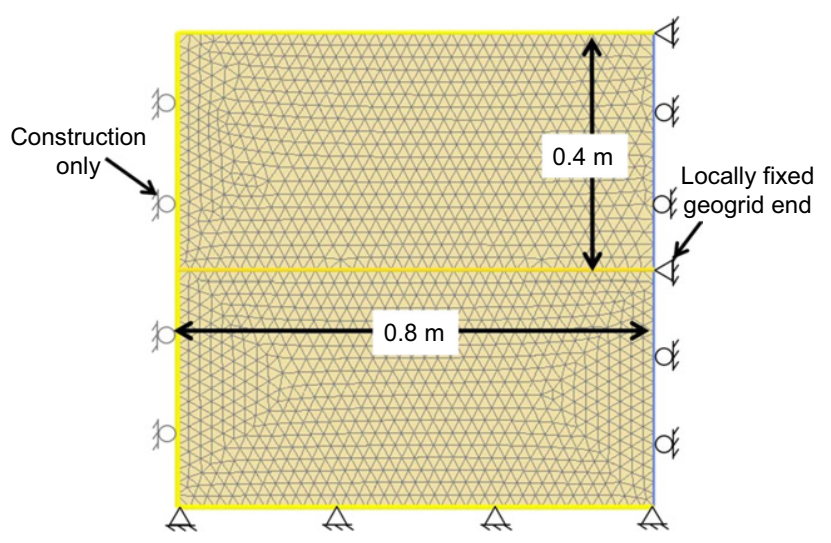

Figure 4. Case study 1 model geometry

They used wrapped layers of polyester geogrid with a maximum tensile strength of $35 \mathrm{kN} / \mathrm{m}$.

Each layer was lightly compacted $\left(5 \mathrm{kN} / \mathrm{m}^{2}\right)$ by a handheld tamper. As the test was constructed in a confined space, the geogrid tail lengths were limited to $1.0 \mathrm{~m}$ and their ends were rigidly fixed to the back of the box to prevent pull-out failure.

The profile of the GRS was measured using photogrammetry through the glass-sided test box at three stages: at full height behind the full height formwork (during construction), at the end of construction (EOC).

The numerical model of this GRS used a fine mesh size, featuring 2648 triangular elements. Its construction consisted of six stages that included the infilling of each layer followed by a compaction stage, until the total height of the structure $(0.8 \mathrm{~m})$ was reached. The final stage of construction modelling was the deactivation of the full height horizontal constraint, causing the structure to deform horizontally (and vertically).

\subsubsection{Case study 2: $3.6 \mathrm{~m}$ high GRS using layer-by-layer construction method \\ This GRS was a $3.6 \mathrm{~m}$ high structure, consisting of six polyester geogrid layers, constructed at an approximately $65^{\circ}$ inclination (Figure 5). The GRS used imported gravel that had properties as displayed in Table 3. It was}


Table 2. Case study 1: soil model and geogrid parameters for Plaxis

\begin{tabular}{|c|c|c|}
\hline Parameter & Description & $\begin{array}{c}\text { Soil } \\
\text { HS-model }\end{array}$ \\
\hline$\varphi\left({ }^{\circ}\right)$ & Plane strain friction angle & 43 \\
\hline$\psi\left({ }^{\circ}\right)$ & Dilation angle & 10 \\
\hline$c\left(\mathrm{kN} / \mathrm{m}^{2}\right)$ & Cohesion & 0.5 \\
\hline$E_{50}^{\text {ref }}\left(\mathrm{kN} / \mathrm{m}^{2}\right)$ & $\begin{array}{l}\text { Secant stiffness in standard drained } \\
\text { triaxial test }\end{array}$ & 30000 \\
\hline$E_{\text {oed }}^{\text {ref }}\left(\mathrm{kN} / \mathrm{m}^{2}\right)$ & $\begin{array}{l}\text { Tangent stiffness for primary } \\
\text { oedometric loading }\end{array}$ & 30000 \\
\hline$E_{\mathrm{ur}}^{\mathrm{ref}}\left(\mathrm{kN} / \mathrm{m}^{2}\right)$ & Unloading reloading stiffness & 90000 \\
\hline$p^{\text {ref }}\left(\mathrm{kN} / \mathrm{m}^{2}\right)$ & Reference stress level & 100 \\
\hline$m(-)$ & Exponent of the Ohde/Janbu Law & 0.5 \\
\hline$R_{\mathrm{f}}(-)$ & Failure ratio & 0.9 \\
\hline$v(-)$ & Poisson's ratio & 0.3 \\
\hline$\gamma\left(\mathrm{kN} / \mathrm{m}^{3}\right)$ & Unit weight (unsaturated) & 16.4 \\
\hline \multirow[t]{2}{*}{$R_{\text {inter }}(-)$} & $\begin{array}{l}\text { Strength reduction factor for } \\
\text { interfaces }\end{array}$ & 1.0 \\
\hline & & $\begin{array}{l}\text { Geogrid } \\
\text { model }\end{array}$ \\
\hline$E A(\mathrm{kN} / \mathrm{m})$ & $\begin{array}{l}\text { Averaged* axial stiffness of geogrid } \\
\text { at } 1 \%\end{array}$ & 350 \\
\hline$N_{\mathrm{p}}(\mathrm{kN} / \mathrm{m})$ & Ultimate tensile force in geogrid & 35 \\
\hline
\end{tabular}

*Value is averaged over $1.0 \mathrm{~m}$ out-of-plane width for plane strain calculation.

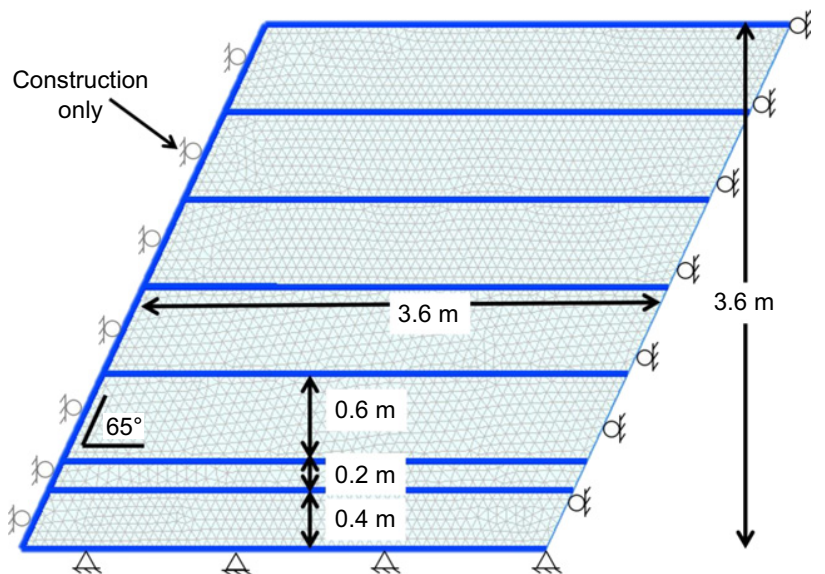

Figure 5. Case study 2 model geometry (adapted from Scotland et al. 2014)

constructed using a layer-by-layer method, with each $0.5 \mathrm{~m}$ layer being relatively well compacted $\left(40 \mathrm{kN} / \mathrm{m}^{2}\right)$ by a vibrating plate. Each wrapped faced layer was constructed behind temporary wooden panels. (In the numerical model this was simulated by an immovable horizontal boundary). The numerical model of the structure featured a fine triangular mesh with 6795 elements. The GRS was founded on a firm sandy clay foundation that in the numerical model was assumed to be immovable for simplicity. An additional horizontal constraint was also added behind the reinforced soil block to prevent global deformation.

The profile of the structure was surveyed during and at the end of construction using a terrestrial laser scanner to survey approximately 10000 indiscriminate points on the face in order to quantify the magnitude and distribution
Table 3. Case study 2: soil model and geogrid parameters for Plaxis (adapted from Scotland et al. 2012)

\begin{tabular}{|l|l|c|}
\hline Parameter & Description & $\begin{array}{c}\text { Soil } \\
\text { HS-model }\end{array}$ \\
& & 35 \\
$\varphi\left({ }^{\circ}\right)$ & Plane strain friction angle & 5 \\
$\psi\left({ }^{\circ}\right)$ & Dilation angle & 0.5 \\
$c\left(\mathrm{kN} / \mathrm{m}^{2}\right)$ & Cohesion & 30000 \\
$E_{50}^{\text {ref }}\left(\mathrm{kN} / \mathrm{m}^{2}\right)$ & Secant stiffness in standard & \\
& $\quad$ drained triaxial test & 30000 \\
$E_{\mathrm{oed}}^{\mathrm{ref}}\left(\mathrm{kN} / \mathrm{m}^{2}\right)$ & Tangent stiffness for primary & \\
& $\quad$ oedometric loading & 90000 \\
$E_{\mathrm{ur}}^{\mathrm{ref}}\left(\mathrm{kN} / \mathrm{m}^{2}\right)$ & Unloading reloading stiffness & 100 \\
$p^{\text {ref }}\left(\mathrm{kN} / \mathrm{m}^{2}\right)$ & Reference stress level & 0.5 \\
$m(-)$ & Exponent of the Ohde/Janbu Law & 0.9 \\
$R_{\mathrm{f}}(-)$ & Failure ratio & 0.3 \\
$v(-)$ & Poisson's ratio & 18 \\
$\gamma\left(\mathrm{kN} / \mathrm{m}^{3}\right)$ & Unit weight (unsaturated) & 1.0 \\
$R_{\mathrm{inter}}(-)$ & Strength reduction factor for & Geogrid \\
& $\quad$ interfaces & model \\
& & 350 \\
$E A(\mathrm{kN} / \mathrm{m})$ & Stiffness of geogrid at 1\% & 35 \\
$N_{\mathrm{p}}(\mathrm{kN} / \mathrm{m})$ & Ultimate tensile force in geogrid & \\
\hline
\end{tabular}

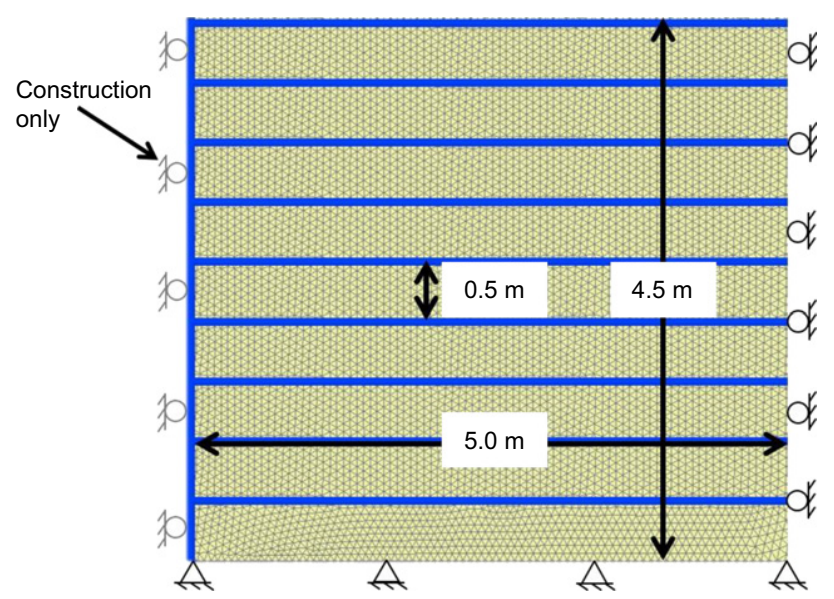

Figure 6. Case study 3 model geometry (adapted from Alexiew and Detert 2008)

of face deformations, as discussed by Scotland et al. (2014). The surveyed profile was compared with the modelled deformation profile at the end of construction.

\subsubsection{Case study 3: $4.5 \mathrm{~m}$ high GRS using full height construction method}

A third case study was modelled using the published details of a laboratory test undertaken by Alexiew and Detert (2008). The structure was a $4.5 \mathrm{~m}$ high, wrapped faced geogrid wall featuring nine layers of $80 \mathrm{kN} / \mathrm{m}$ polyester geogrid (Figure 6) and was founded on the concrete floor of the laboratory. The properties of the materials used are presented in Table 4, which has been adapted from Alexiew and Detert (2008). Outward lateral face deformation of the GRS was monitored using 12 linear variable differential transformers (LVDTs), as it was tested post-construction, using a load plate. A surcharge of up to $500 \mathrm{kN} / \mathrm{m}^{2}$ was applied over a $0.5 \mathrm{~m}^{2}$ area, $1.0 \mathrm{~m}$ from its face. 
Table 4. Case study 3: soil model and geogrid parameters for Plaxis (adapted from Alexiew and Detert 2008)

\begin{tabular}{|l|l|c|}
\hline Parameter & Description & $\begin{array}{c}\text { Soil } \\
\text { HS-model }\end{array}$ \\
& & \\
$\varphi\left({ }^{\circ}\right)$ & Plane strain friction angle & 40 \\
$\psi\left({ }^{\circ}\right)$ & Dilation angle & 10 \\
$c\left(\mathrm{kN} / \mathrm{m}^{2}\right)$ & Cohesion & 0.5 \\
$E_{50}^{\mathrm{ref}}\left(\mathrm{kN} / \mathrm{m}^{2}\right)$ & Secant stiffness in standard drained & 110000 \\
& $\quad$ triaxial test & 110000 \\
$E_{\mathrm{oed}}^{\mathrm{ref}}\left(\mathrm{kN} / \mathrm{m}^{2}\right)$ & Tangent stiffness for primary & \\
& $\quad$ oedometric loading & 330000 \\
$E_{\mathrm{ur}}^{\mathrm{ref}}\left(\mathrm{kN} / \mathrm{m}^{2}\right)$ & Unloading reloading stiffness & 100 \\
$p^{\mathrm{ref}}\left(\mathrm{kN} / \mathrm{m}^{2}\right)$ & Reference stress level & 0.5 \\
$m(-)$ & Exponent of the Ohde/Janbu Law & 0.9 \\
$R_{\mathrm{f}}(-)$ & Failure ratio & 0.3 \\
$v(-)$ & Poisson's ratio & 20 \\
$\gamma\left(\mathrm{kN} / \mathrm{m}^{3}\right)$ & Unit weight (unsaturated) & 1.0 \\
$R_{\mathrm{inter}}(-)$ & Strength reduction factor for & Geogrid \\
& $\quad$ interfaces & model \\
& & 1600 \\
$E A(\mathrm{kN} / \mathrm{m})$ & Stiffness of PVA geogrid at 1\% & 80 \\
$N_{\mathrm{p}}(\mathrm{kN} / \mathrm{m})$ & Ultimate tensile force in geogrid & \\
\hline
\end{tabular}

Case study 3 was constructed using the full height method and was founded on a concrete floor to prevent global movement. Each $0.5 \mathrm{~m}$ thick wrapped reinforcement layer was compacted during construction; however, as no data was available a compacting force of $40 \mathrm{kN} / \mathrm{m}^{2}$ was assumed in the numerical model. The geometry of the numerical model is shown in Figure 6, and featured a fine mesh with 10797 triangular elements.

\subsubsection{Numerical and measured deformation comparison}

\subsubsection{Overview}

GRS profiles from each of the three numerical models were compared with their measured profiles at the EOC and under loading (where data was available). These results were compared by assessing the capability of each numerical model to assess the maximum horizontal deformation and average deformation with height, as well as a qualitative shape assessment.

\subsubsection{Case study 1: $0.8 \mathrm{~m}$ high model using the full} height construction method

Comparing both measured and modelled profiles (Figure 7), there were similarities in the deformed shape for both layers. Measured average horizontal deformation, $0.024 \mathrm{~m}$, was underestimated by the numerical model by $13 \%$; whereas maximum deformation, $0.046 \mathrm{~m}$, was underestimated by $30 \%$.

\subsubsection{Case study 2: 3.6 m high GRS using layer-by-layer construction method}

The profile of the numerical model of case study 2 was compared with the measured results described by Scotland et al. (2014) in Figure 8. Average horizontal deformation, of the face, was underestimated by the numerical model by $32 \%$, and the maximum deformation, $0.129 \mathrm{~m}$, was underestimated by $13 \%$. Both profiles also showed higher deformation in the lower half of the GRS,

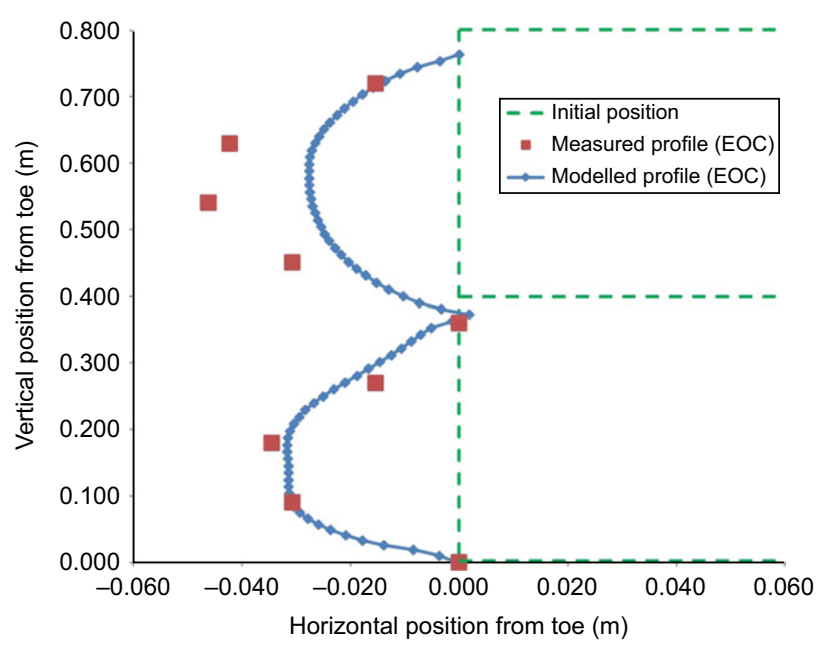

Figure 7. Case study 1: measured and modelled comparison

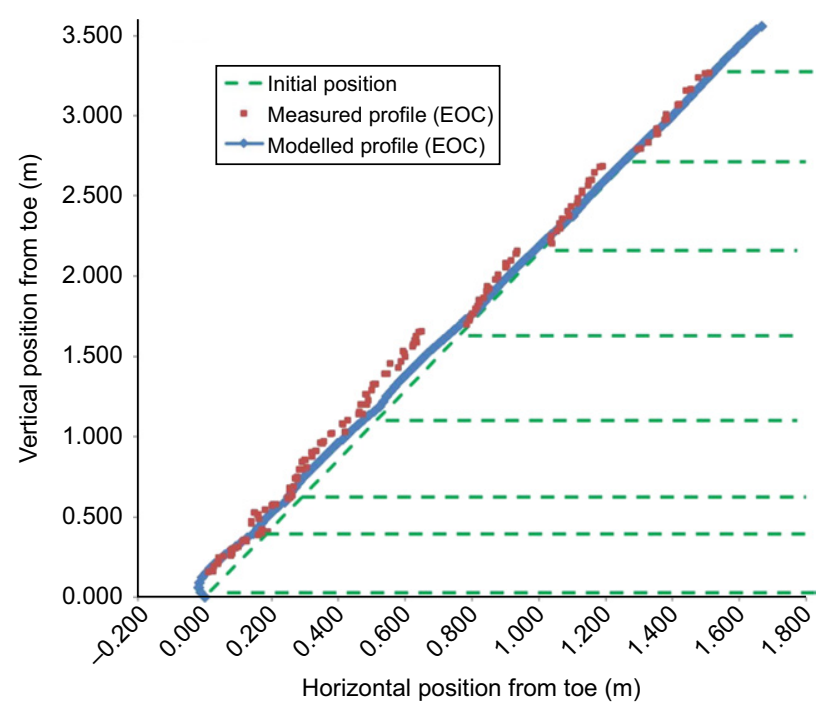

Figure 8. Case study 2: measured and modelled comparison

where average deformation was 0.075 and $0.066 \mathrm{~m}$ for the measured and modelled profiles, respectively. These results were in contrast to the top half, where it was 0.030 and $0.013 \mathrm{~m}$, respectively.

\subsubsection{Case study 3: 4.5 m high GRS using full height construction method}

Figure 9, displays the modelled and measured profiles for case study 3. No measured construction deformation data was given by Alexiew and Detert (2008), so only postconstruction deformation data is compared in Figure 9. Measured average horizontal deformation, $0.015 \mathrm{~m}$, was overestimated by the numerical model by $140 \%$, and the measured maximum deformation, $0.031 \mathrm{~m}$, was overestimated by $92 \%$.

\subsection{Local parameter sensitivity}

Numerical models are sensitive to the values given to input parameters. The nine constitutive parameters of the HS model and geogrid model in case study 3 (Table 4) were independently analysed using the 'one at a time' methodology. As discussed in Section 3.2, the nine 
parameters analysed were: $\varphi, \psi, c, E_{50}^{\mathrm{ref}}, E_{\mathrm{oed}}^{\mathrm{ref}}, E_{\mathrm{ur}}^{\mathrm{ref}}, m, v, \gamma$ and $E A$. Each variable was altered independently and their effect on horizontal deformation evaluated.

Of these nine parameters, the most sensitive was the value used to represent the internal friction angle, $\varphi$ of the soil. Comparing values for $\varphi$ between $30^{\circ}$ and $45^{\circ}$, the construction and post-construction deformation can be seen to decrease linearly as it is related with increased frictional shear strength, varying over the range by as much as 50 and $30 \%$, respectively (Figure 10).

The consequence of including a small cohesive shear strength component $\left(c=0.5 \mathrm{kN} / \mathrm{m}^{2}\right)$, to prevent singularity errors within the FE program, is shown in Figure 11. Over

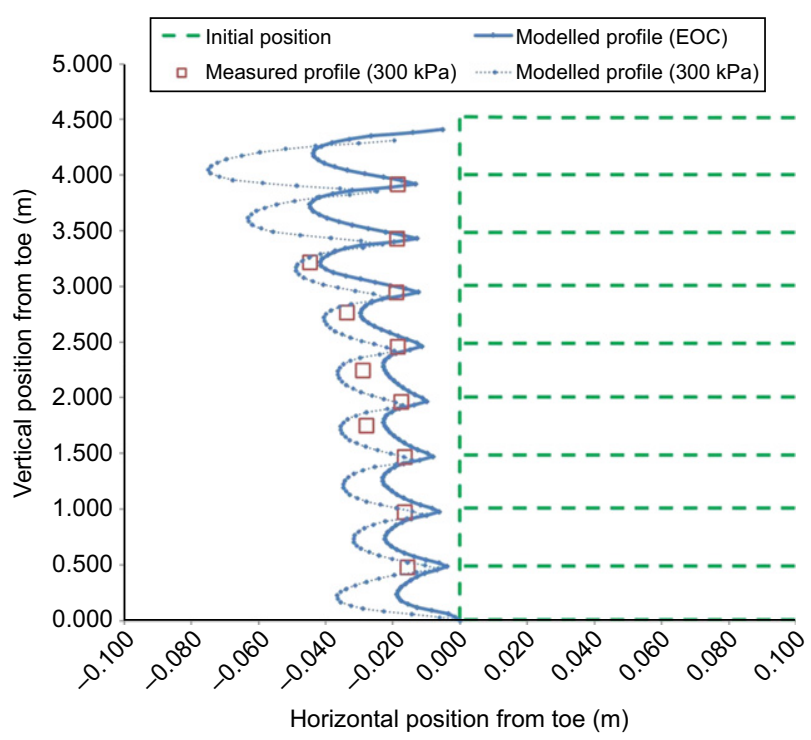

Figure 9. Case study 3: measured and modelled comparison

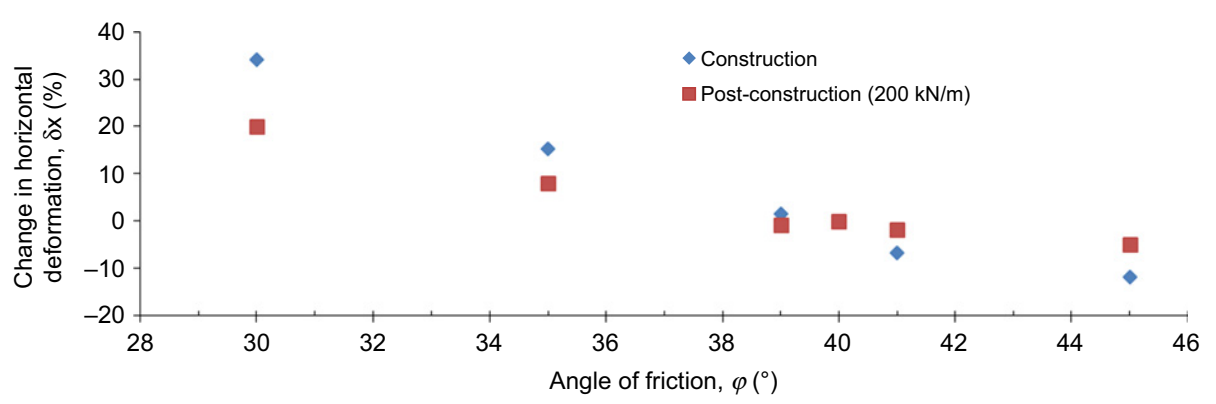

Figure 10. Local sensitivity analysis - angle of frictional shear strength. Reference for evaluation model: $\varphi=40^{\circ}: \delta x_{\mathrm{c}}=0.045 \mathrm{~m}$, $\delta x_{\mathrm{pc}}=0.075 \mathrm{~m}$

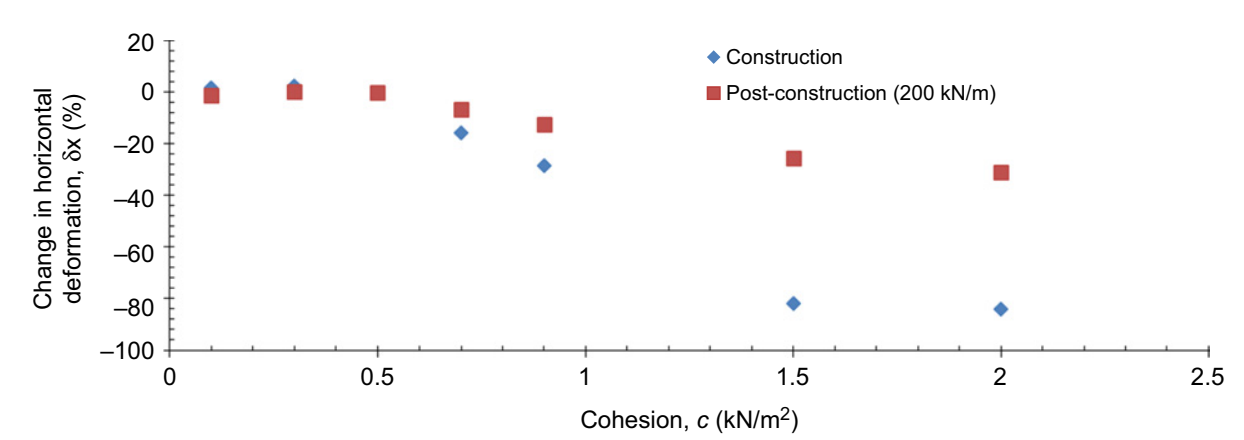

Figure 11. Local sensitivity analysis - cohesive shear strength. Reference for evaluation model: $c=0.5 \mathrm{kN} / \mathrm{m}^{2}: \delta x_{\mathrm{c}}=0.045 \mathrm{~m}$, $\delta x_{\mathrm{pc}}=0.075 \mathrm{~m}$

a range of 0.1 to $0.5 \mathrm{kN} / \mathrm{m}^{2}$, it has relatively little influence $(-1.6 \%$ max. construction and $+1.3 \%$ max. post-construction deformations, respectively). Its influence on horizontal deformation disproportionately increased when $c$ was increased to $0.9 \mathrm{kN} / \mathrm{m}^{2}(-29.5$ and $-11.4 \%)$.

The sensitivity analysis of tangent soil stiffness for primary oedometric loading, $E_{50}^{\text {ref }}$, considered values between 10 and $110 \mathrm{kN} / \mathrm{m}$. It was found to influence construction deformation by $-0.21 E_{50}^{\mathrm{ref}}$ and post-construction deformation by $-0.73 E_{50}^{\mathrm{ref}}$. The sensitivity of the remaining soil parameters $\left(\psi, E_{\mathrm{oed}}^{\mathrm{ref}}, E_{\mathrm{ur}}^{\mathrm{ref}}, m, v\right)$ was not significant (i.e. greater than $0.05 \partial d x / \partial X$ ).

In the selection of the geogrid model parameters, it was assumed that there was a simple perfectly elastic-plastic relationship. The geogrid stiffness for each model was obtained using wide-width tensile tests and did not include creep, for the reasons stated in Section 3.2.3 (Figure 12). It showed no significant difference in affecting construction deformation between 800 and $2000 \mathrm{kN} / \mathrm{m}(+10$ to $-5 \%)$, whereas post-construction deformation increased for weaker geogrids by as much as $40 \%$. This highlights the need for careful selection of geogrid stiffness.

\section{CONSTRUCTION METHOD ANALYSIS}

\subsection{Overview}

In this section, the numerical modelling method was expanded to evaluate the effect of both construction methods on construction and loading deformation. Case study 3 , as the most typical GRS of the three case studies examined, was adapted for use as an evaluation model. The reference properties of the evaluation model remained the

Post-construction $(200 \mathrm{kN} / \mathrm{m})$

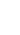
(n) 


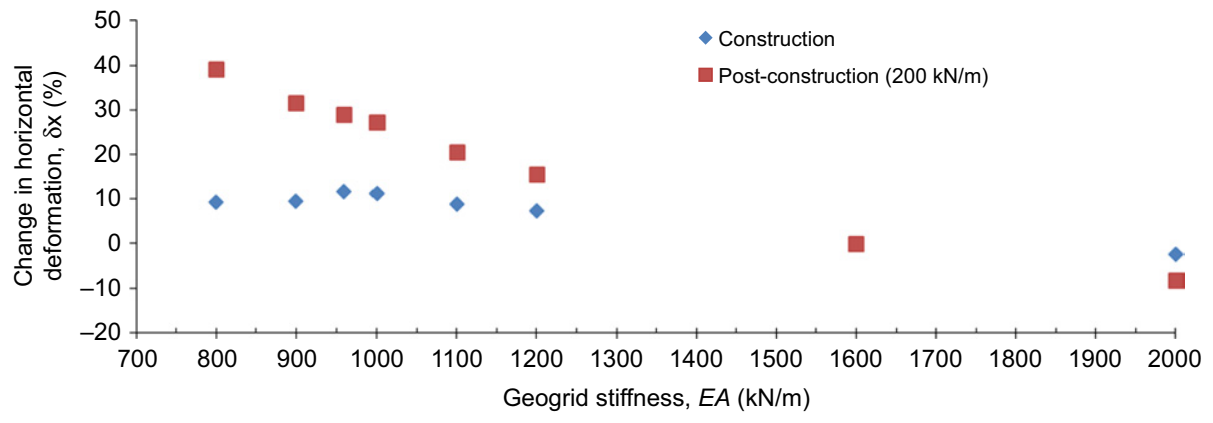

Figure 12. Local sensitivity analysis - geogrid stiffness. Reference for evaluation model: $E A=1600 \mathrm{kN} / \mathrm{m}: \delta x_{\mathrm{c}}=0.045 \mathrm{~m}, \delta x_{\mathrm{pc}}=0.075 \mathrm{~m}$

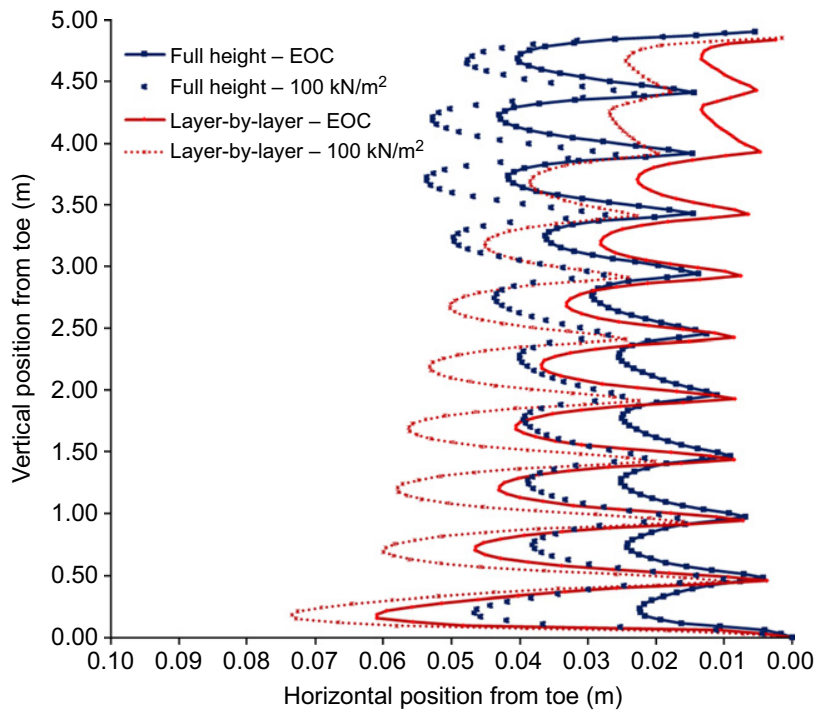

Figure 13. Construction method comparison in the evaluation numerical model $(H=5.0 \mathrm{~m}, L=3.5 \mathrm{~m})$

same (Table 4) and the geometry was modified for simplicity. The model height, $H$, was increased to $5.0 \mathrm{~m}$, and reinforcement length, $L$, restricted to $70 \%$ of the total height, forming a GRS consisting of ten $0.5 \mathrm{~m}$ layers. Figure 13 displays the profiles of both numerically modelled construction methods: full height and layer-by-layer.

Comparing both methods at the EOC, the GRS constructed using full height formwork produced a less deformed structure with maximum deformation occurring in the highest layers $(0.044 \mathrm{~m})$. In contrast, the model using a layer-by-layer construction method features an approximately linear decrease in deformation towards the top of the structure, with a maximum deformation occurring in the lowest layer $(0.062 \mathrm{~m})$.

Both numerical models were subjected to a surcharge of $100 \mathrm{kN} / \mathrm{m}^{2}$ acting over the crest of the structure. Figure 13 shows over $50 \%$ less additional deformation occurred when using the layer-by-layer method $(0.018 \mathrm{~m})$, than using the full height model $(0.024 \mathrm{~m})$. This provides evidence that the construction method plays an important role in determining face deformation. The layers that underwent greater deformation during construction also underwent the lowest deformation during loading. Total cumulative (construction and loading) deformation was higher in the layer-by-layer model $(0.074 \mathrm{~m})$ than for the full height structure $(0.053 \mathrm{~m})$.

\subsection{Height and surcharge with construction method}

The numerical modelling was extended to consider structure heights: between 2.5 and $10 \mathrm{~m}$ (Figure 14). For each height, the model featured equally spaced reinforcement lengths, $L$, remaining equal to $70 \%$ of the height, $H$. Maximum construction deformation for both construction methods displayed a strongly positive linear relationship with height $(0.004 H)$. The maximum deformation occurred in the lowest layers for all of the models. This data suggests that for the analysed case the layer-by-layer method would cause $0.030 \mathrm{~m}$ more construction deformation than the full height method.

Numerical modelling was also extended to include post-construction surcharges of 0 to $200 \mathrm{kN} / \mathrm{m}^{2}$. Both construction methods showed approximately linear relationships between maximum deformation and applied surcharge loading (Figure 15). In all cases, the maximum deformation occurred in the highest layers of each model. This data suggests that GRS built using full height formwork, may deform 50\% more, under a post-construction surcharge, than using the layer-by-layer method.

\subsection{Construction method effect guidance}

Based on the extended analysis of structure height and surcharge (Figures 14 and 15), for wrapped GRS structures, constructed with full height temporary face support, the following guidance is presented.

- Maximum construction deformation (m):

$$
\delta x_{\mathrm{c}}=\frac{H}{250}+0.030
$$

- Maximum post-construction deformation (m):

$$
\delta x_{\mathrm{pc}}=0.00018 \times \Delta \sigma_{\mathrm{v}}
$$

Alternatively for GRS constructed using a layer-by-layer method:

- Maximum construction deformation (m):

$$
\delta x_{\mathrm{c}}=\frac{H}{250}+0.060
$$

- Maximum post-construction deformation (m):

$$
\delta x_{\mathrm{pc}}=0.00012 \times \Delta \sigma_{\mathrm{v}}
$$




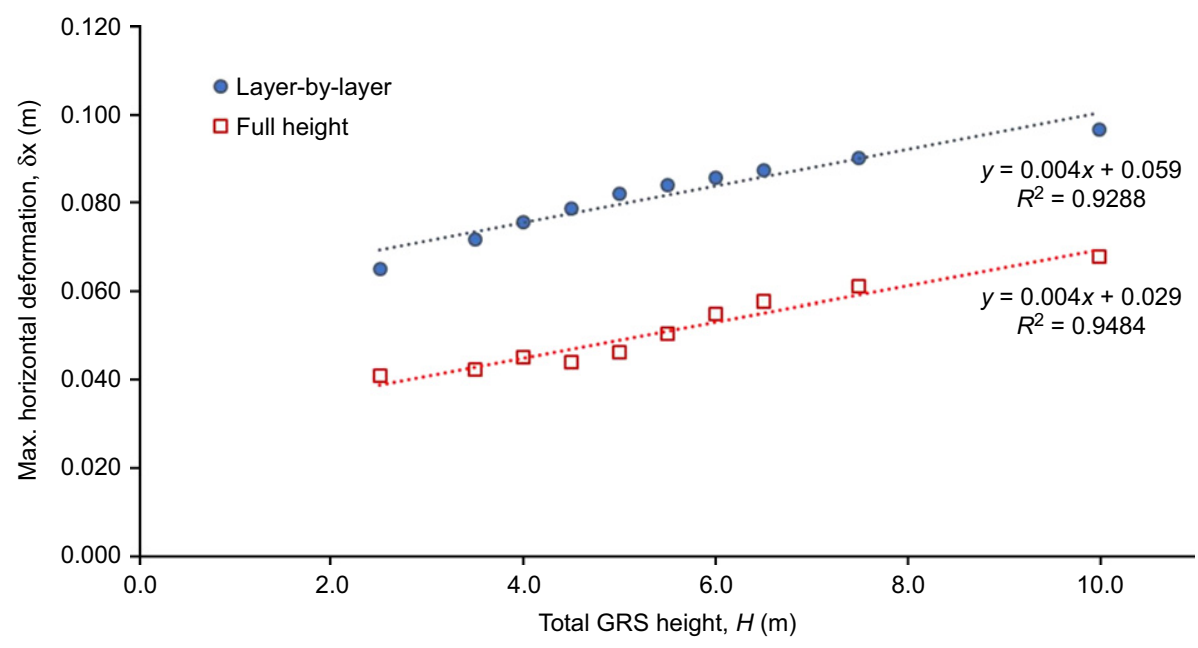

Figure 14. Construction technique and maximum construction deformation

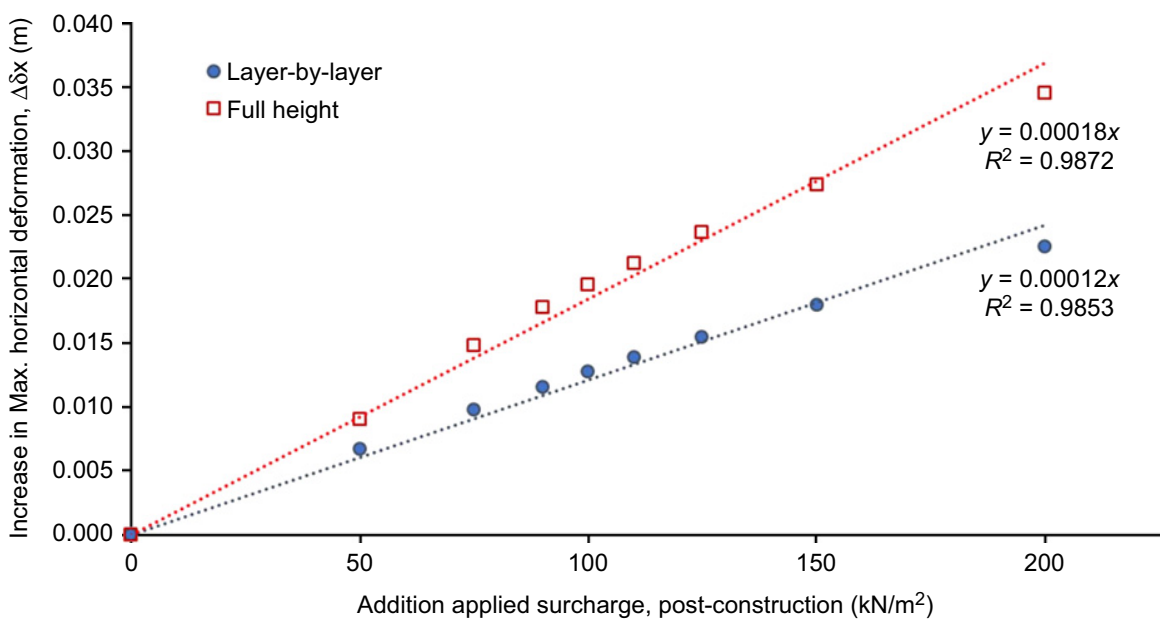

Figure 15. Construction technique and maximum surcharge induced deformation

These values are provided for initial guidance only and, where possible, should be validated by further observation and numerical modelling to determine the reliability of these simple expressions.

\subsection{Validation of the deformation guidance}

\subsubsection{Case studies}

In Table 5, the proposed guidance (Section 4.3) is compared with the measured data from the three case studies described earlier in Section 3.3. The maximum measured deformation for case studies 1,2 and 3 , was $0.0462,0.129$ and $0.041 \mathrm{~m}$, respectively. Using the new guidance this was estimated as $0.062,0.074$ and 0.084 , respectively. All the case studies used to validate this model were based on GRS with high quality granular soils $\left(\varphi>30^{\circ}\right)$. As alluded to in Section 3.4, different results will be observed for variations in soil strength, geogrid stiffness and compaction, among other properties.

This guidance has been developed for vertical GRS, the most sensitive condition, and does not account for facing batter in sloping structures. Work by Bathurst et al. (2008), suggests a non-linear reduction factor between facing batter and stress in the structure, but it is unclear
Table 5. Deformation guidance and case studies comparison

\begin{tabular}{|l|c|c|c|c|}
\hline $\begin{array}{l}\text { Case } \\
\text { study }\end{array}$ & $\begin{array}{c}\text { Height, } \\
H(\mathrm{~m})\end{array}$ & $\begin{array}{c}\text { Surcharge, } \\
\Delta \sigma_{\mathrm{v}}\end{array}$ & $\begin{array}{c}\text { Measured, } \\
\delta x(\mathrm{~m})\end{array}$ & $\begin{array}{c}\text { Predicted, } \\
\delta x(\mathrm{~m})\end{array}$ \\
\hline 1 & 0.8 & - & 0.0462 & 0.062 \\
2 & 3.6 & - & 0.129 & 0.074 \\
3 & 4.5 & $300 \mathrm{kN} / \mathrm{m}^{2}$ & 0.041 & 0.084 \\
\hline
\end{tabular}

how this translates to construction method deformation, without further detailed analysis.

\subsubsection{Comparison with other deformation relationships} The deformation guidance for construction deformation (Equations 1 and 3) is in line with similar empirically based guidance (Christopher 1993; Lee 2000; Bathurst et al. 2002). Figure 16 compares these guide-predicted construction deformations for varying heights and the parameters of case study 3 (Table 4). As described in Section 2.3, each deformation guide has been developed by considering differing variables and case studies (Table 1), and as a result the derived deformations do 


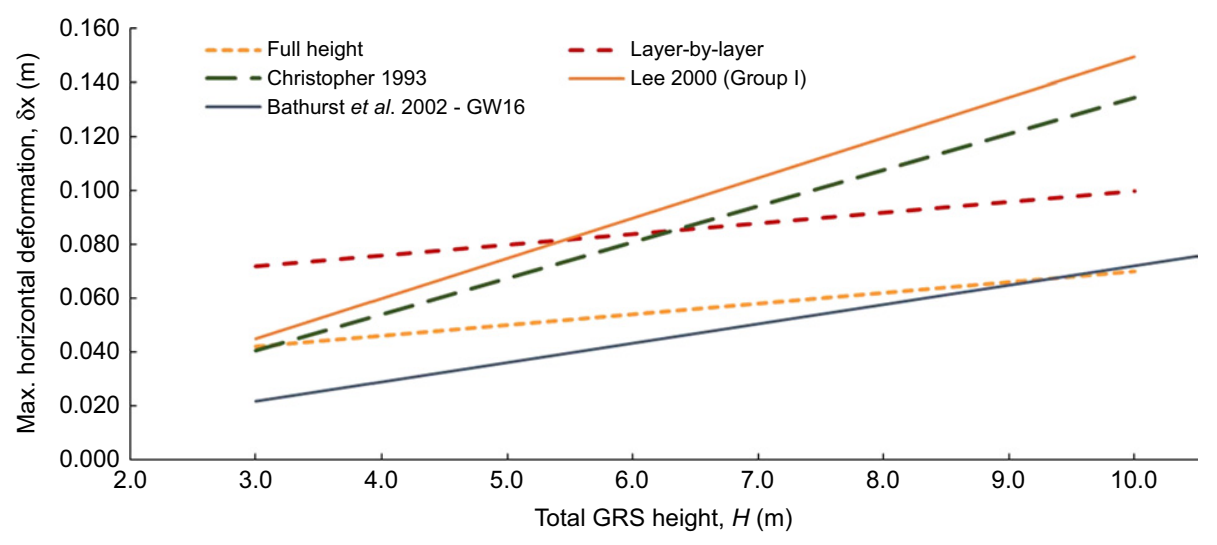

Figure 16. Construction deformation guide comparison for $L=0.7 H, \varphi=40^{\circ}, S_{\mathrm{v}}=0.5 \mathrm{~m}, E A=1600 \mathrm{kN} / \mathrm{m}$ (Christopher 1993; Lee 2000; Bathurst et al. 2002)

not agree perfectly. The models all show a positive linear relationship, between $H$ and deformation.

Bathurst et al. (2002) provide a height-normalised, case-study-based reference. Face deformation can be estimated based on comparison with a well instrumented wrapped faced case study (GW16), which is one of three case studies.

Based primarily on GRS with wrapped facing and employing a range of variables, Lee (2000), predicts the highest deformation, for all but the smallest structures $(H<5.0 \mathrm{~m})$. Closely followed by Christopher (1993), based primarily on the relationship between height $H$ and reinforcement length, $L$.

Both models proposed in this paper (Equations 1 and 3), predict deformations between the three existing models. The deformations predicted by Equation 1 for full height construction closely follow the Bathurst et al. (2002) model. whereas for layer-by-layer construction, Equation 3 projects a larger deformation than any other model for smaller structures $(<5.0 \mathrm{~m})$, but drops below the Christopher (1993) and Lee (2000) models for high structures $(>6.5 \mathrm{~m})$. Of particular note is that all existing guidance underestimates the construction deformations for walls lower than $5 \mathrm{~m}$ in height when constructed using the layer-by-layer method.

\section{DISCUSSION}

\subsection{Numerical modelling discrepancies}

\subsubsection{Geometrical simplifications}

A proportion of the underestimation of deformation for case study 2 (Table 5), can be explained by the simplified initial position of the GRS under construction. The geometry of case study 2 (Figure 5), was not as uniform as those of case studies 1 and 3 , and varied along the running length of the structure. For the purpose of this modelling a consistent angle of $65^{\circ}$ was assumed based on the pre-construction design. This simplification excluded the geometrical imperfections present in this structure and which are common in all GRS, such as variations in inclination and small step backs between layers (Figure 5).

\subsubsection{Soil and geogrid modelling errors}

Errors between the numerical model and reality can be caused by inaccurate input data for the soil and geogrid models. The sensitivity of the parameters involved was assessed in Section 3.4, and showed the most sensitive parameters to be $\varphi, c, E_{50}^{\text {ref }}$ and $E A$. Other soil models were considered such as a linear-elastic perfectly plastic model or a soil model with different small strain characteristics, but the HS model was considered to replicate the important characteristics of granular soil behaviour that control the GRS behaviour, yet requiring parameters that can be reasonably obtained.

The calculation of deformation in FE programs also includes inaccuracies. The staged construction of numerical models in Plaxis can lead to large settlements, due to pre-displacements at the start of each stage. However the program includes a post-calculation option, 'sum-phase displacement', to ignore this and present a more accurate model. This feature was considered but it was found to have no effect on horizontal displacements and therefore it was not used in the construction method evaluation. In the calculations, the tolerated errors in the partial difference equations of the numerical model were undertaken, to an accuracy of $1 \%$. The mesh size of the model was also considered, but showed that no significant variation $(<5 \%)$ was detected when the mesh density was over 200 elements $/ \mathrm{m}^{2}$. In FE analysis, the soils model was simulated as a homogenised continuum, which cannot consider the relative movement of individual particles. This may lead to an underestimation of movement internally, with soil particles passing through geogrid apertures. Numerical methods such as the discrete element modelling, in which individual particles are modelled as finite elements, are only beginning to be used to assess this (Wang et al. 2014).

The modelling of simple geogrid elements in FE programs can result in residual forces in the final nodes as the geogrid is connected to the soil mesh. There are numerical programming tools which can be used to transfer stresses from these final nodes through the geogrid (Teixeira et al. 2007). However, for the conditions considered in this particular analysis, such a tool was not considered. In addition, more advanced hyperbolic 
geogrid stiffness models, could have been considered to more accurately represent creep and stiffness softening (Kaliakin et al. 2000), although the case studies and analysis considered in this study were short term.

\subsubsection{Validity of numerical modelling approach}

The numerical modelling approach was based on the reinforced soil zone, considering face and internal GRS deformation in the horizontal direction only (Section 2.1). As a result it was limited to case studies in which there was no movement outside the reinforced soil zone. The numerical model was used to model three case studies in which maximum and average wall face deformations were modelled to an accuracy of -30 to $92 \%$ and -32 to $140 \%$ of measured values, respectively. These ranges were a function of the material models selected, material parameter uncertainty, simplifications in the model geometries in comparison with the case study as constructed geometries and the approaches used to replicate the layer-by-layer and full face construction processes. However, the magnitudes of deformation, the close agreement between the shapes of the surface deformation profiles and the consistency of trends between the modelled and measured behaviours all provide justification for using the presented modelling approach to investigate the effects of construction method and trends in lateral deformations related to GRS geometry.

\subsection{Case study data}

The deformations measured in each case study contain varying degrees of uncertainty as they used different monitoring devices. The accuracy of LVDTs $( \pm 0.1 \mathrm{~mm})$ from case study 3 is typically higher than photogrammetry $( \pm 5 \mathrm{~mm})$ as used in case study 1 or laser scanning $( \pm 5 \mathrm{~mm})$ as used in case study 2 (Scotland et al. 2014). However, photogrammetry and laser scanning have very high measured spatial densities, allowing the analysis of large numbers of cross-sections that do not need to be predetermined.

\subsection{Deformation guidance validity}

The deformation guidance (Equations 1-4) outlined in Section 4.4, has been developed based on a specific range of high quality $\left(\varphi>35^{\circ}\right)$ granular-filled case studies and should not be taken out of context. There are many other factors contributing to deformational performance in GRS, such as compactive effort (Bathurst et al. 2009; Ehrlich et al. 2012), global and relative reinforcement stiffness (Christopher 1993; Ehrlich and Mitchell 1994) among others. Further work is necessary to adapt the model for these variables and application with granular fills that have low shear strength and cohesive fills.

\section{CONCLUSIONS}

The development of design methods and guidance for GRS has been historically focused on their ultimate limit states, such as pull-out, rupture and global stability failure. However, as these have become more refined, serviceability limits have become more important. Although there are many deformation databases and design charts available providing guidance on sensitivity of deformations for a range of variables, methods of construction are not currently included.

This paper presents a simple numerical model methodology (Section 3.2) for modelling two construction methods: GRS with full height temporary formwork or GRS with layer-by-layer temporary formwork. This modelling approach was validated using three granularfilled GRS case studies. Following a parametric analysis of deformation and height, simple deformation guidance was outlined (Section 4.3), showing a $0.030 \mathrm{~m}$ increase in construction deformation when a layer-by-layer construction method is used. In contrast, the analysis suggests $50 \%$ less deformation under load is predicted after construction using the layer-by-layer approach, in comparison with the full height construction technique. Importantly, for low wall height structures constructed using the layer-by-layer method, $<5 \mathrm{~m}$, the present study indicates that horizontal face deformations are underestimated by current guidance.

The use of the results from this study to provide guidance on GRS deformations following construction and under load is limited to the range of cases using high quality reinforced fill. However, the outlined numerical method, coupled with further measured data could be used to extend the guidance to include GRS constructed using marginal soils, where serviceability limit state can control design.

\section{ACKNOWLEDGEMENTS}

The authors wish to thank the EPSRC for providing funding through the Centre for Innovative Construction Engineering (CICE) at Loughborough University and Huesker (UK) Limited for funding and supporting this research project.

\section{NOTATION}

Basic SI units are given in parentheses.

$c$ cohesion $\left(\mathrm{N} / \mathrm{m}^{2}\right)$

$E A$ stiffness of geogrid at $1 \%(\mathrm{~N} / \mathrm{m})$

$E_{50}^{\text {ref }}$ tangent stiffness for primary oedometric loading $\left(\mathrm{N} / \mathrm{m}^{2}\right)$

$E_{\text {oed }}^{\text {ref }} \quad$ secant stiffness in standard drained triaxial test $\left(\mathrm{N} / \mathrm{m}^{2}\right)$

$E_{\text {ur }}^{\text {ref }}$ unloading reloading stiffness $\left(\mathrm{N} / \mathrm{m}^{2}\right)$

$H$ height (m)

$L \quad$ reinforcement length $(\mathrm{m})$

$m$ power exponent of the Ohde/Janbu law (-)

$N_{\mathrm{p}} \quad$ ultimate tensile force in geogrid ( $\left.\mathrm{N} / \mathrm{m}\right)$

$p^{\text {ref }} \quad$ reference stress level $\left(\mathrm{N} / \mathrm{m}^{2}\right)$

$R_{\text {inter }}$ strength reduction factor for interfaces (-)

$S_{\mathrm{v}} \quad$ reinforcement spacing $(\mathrm{m})$

$\Delta \sigma_{\mathrm{v}}$ additional vertical loading $\left(\mathrm{N} / \mathrm{m}^{2}\right)$ 
$\delta x_{\mathrm{c}} \quad$ lateral deformation during construction (m)

$\delta x_{\mathrm{pc}} \quad$ lateral deformation post-construction (m)

$\gamma \quad$ unit weight (unsaturated) $\left(\mathrm{N} / \mathrm{m}^{3}\right)$

$\varepsilon \quad$ strain in geogrid (-)

$\varphi \quad$ plane strain friction angle $\left(^{\circ}\right)$

$v$ Poisson's ratio $(-)$

$\psi \quad$ dilation angle $\left({ }^{\circ}\right)$

\section{REFERENCES}

AASHTO (American Association of State Highway and Transportation Officials) (2012). LRFD Bridge Design Specifications, AASHTO, Washington, DC, USA,

AFN (Association Francaise de Normalisation) (2009). NF P94-270: Calcul Geotéchnique - Ouvrages de Soutènement - Remblais Renforcés et Massifs en Sol Cloué, AFN, Paris, France, (in French).

Alexiew, D. \& Detert, O. (2008). Analytical and numerical analyses of a real scaled geogrid reinforced bridge abutment loading test Proceedings of the 4th European Conference of Geosynthetics, Edinburgh, UK, September 2008, paper 257, 8 p.

Allen, T. M. \& Bathurst, R. J. (2015). Improved simplified method for prediction of loads in reinforced soil walls. Journal of Geotechnical and Geoenvironmental Engineering, 141, No. 11, 04015049.

Allen, T. M. \& Bathurst, R. J. (2002). Soil reinforcement loads in geosynthetic walls at working stress conditions. Geosynthetics International, 9, No. 5-6, 525-566.

Allen, T. M., Bathurst, R. J., Holtz, R. D., Walters, D. L. \& Lee, W. F. (2003). A new working stress method for prediction of reinforcement loads in geosynthetic walls. Canadian Geotechnical Journal, 40, No. 5, 976-994.

Anubhav, S. \& Basudhar, P. K. (2011). Numerical modelling of surface strip footings resting on double-faced wrap-around vertical reinforced soil walls. Geosynthetics International, 18, No. 1, 21-34.

Bathurst, R. J., Allen, T. M. \& Walters, D. L. (2002). Short-term strain and deformation behaviour of geosynthetic walls at working stress conditions. Geosynthetics International, 9, No. 5-6, 451-482.

Bathurst, R. J., Vlachopoulos, N., Walters, D. L., Burgess, P. G. \& Allen, T. M. (2006). The influence of facing stiffness on the performance of two geosynthetic reinforced soil retaining walls. Canadian Geotechnical Journal, 43, No. 12, 1225-1237.

Bathurst, R. J., Miyata, Y., Nernheim, A. \& Allen, T. M. (2008) Refinement of k-stiffness method for geosynthetic-reinforced soil walls. Geosynthetics International, 15, No. 4, 269-295.

Bathurst, R. J., Nernheim, A., Walters, D. L., Allen, T. M., Burgess, P. \& Saunders, D. D. (2009) Influence of reinforcement stiffness and compaction on the performance of four geosynthetic-reinforced soil walls. Geosynthetics International, 16, No. 1, 43-59.

Bathurst, R. J., Miyata, Y. \& Allen, T. M. (2010). Facing displacements in geosynthetic reinforced soil walls. Proceedings of Earth Retention Conference 3, Belleview, Washington, USA, August 2010, pp. $442-459$.

Benjamim, C. V. S., Zornberg, J. G. \& Bueno, B. S. (2007). Field monitoring evaluation of geotextile-reinforced soil-retaining walls. Geosynthetics International, 14, No. 2, 100-118.

Bolton, M. D. (1986). The strength and dilatancy of sands. Geotechnique, 36, No. 1, 65-78.

BSI (British Standards Institute) (2004). BS EN 1997-1: Geotechnical Design: Part 1. BSI, London, UK,

BSI (2010). BS 8006-1: Code of Practice for Strengthened/Reinforced Soils and other Fills. BSI, London, UK.

Bussert, F. \& Cavanaugh, J. (2010). Recent research and future implications of the actual behaviour of geogrids in reinforced soil. Proceedings of Earth Retention Conference 3, Belleview, Washington, USA, August 2010, pp. 460-477.

Chew, S. H. \& Mitchell, J. K. (1994). Deformation evaluation procedure for reinforced soil walls. Proceedings of 5 th International Conference on Geotextiles, Geomembranes and Related Products, Singapore, September 1994, pp. 171-176.

Christopher, B. R. (1993). Deformation Response and Wall Stiffness in Relation to Reinforced Soil Wall Design, PhD thesis, Purdue University, West Lafayette, Indianna, USA.

Damians, I., Bathurst, R. J., Josa, A. \& Lloret, A. (2015). Numerical analysis of an instrumented steel-reinforced soil wall. International Journal of Geomechanics, 15, No. 1, 04014037.

DGG (Deutche Gesellschaft für Geotechnik) (2011). EBGEO Recommendations for Design and Analysis of Earth Structures using Geosynthetic Reinforcements, Ernst and Sohn, Munich, Germany.

Ehrlich, M. \& Mirmoradi, S. H. (2013). Evaluation of the effects of facing stiffness and toe resistance on the behavior of GRS walls. Geotextiles and Geomembranes, 40, 28-36.

Ehrlich, M. \& Mitchell, J. K. (1994). Working stress design method for reinforced soil walls. Journal of Geotechnical Engineering, 120, No. 4, 625-645.

Ehrlich, M., Mirmoradi, S. H. \& Saramago, R. P. (2012). Evaluation of the effect of compaction on the behavior of geosynthetic-reinforced soil walls. Geotextiles and Geomembranes, 34, 108-115.

Giroud, J. P., Fluet, J. E. Jr \& Gross, B. A. (1989). FHWA-HI-89-002. Geotextile Engineering Workshop-Design Examples, Federal Highway Administration, Washington, DC, USA.

Guler, E., Hamderi, M. \& Demirkan, M. M. (2007). Numerical analysis of reinforced soil-retaining wall structures with cohesive and granular backfills. Geosynthetic International, 14, No. 6, 330-345.

Hatami, K. \& Bathurst, R. J. (2005). Development and verification of a numerical model for the analysis of geosynthetic-reinforced soil segmental walls under working streshrlic conditions. Canadian Geotechnical Journal, 42, No. 4, 1066-1085.

Herold, A. \& Wolffersdorff, P. (2009). The use of hardening soil model with small-strain stiffness for serviceability limit state analyses of GRE structures. Proceedings of GeoAfrica 1, Cape Town, South Africa, September 2009,

Huang, B., Bathurst, R. J. \& Hatami, K. (2009) Numerical study of reinforced soil segmental walls using three different constitutive soil models. Journal of Geotechnical and Geoenvironmental Engineering, 135, No. 11, 1486-1498.

Jewell, R. A. \& Milligan, G. W. (1989). Deformation calculation for reinforced soil walls. Proceedings of 12th International Conference on Soil Mechanics and Foundation Engineering, Rio de Janeiro, Brazil, August 1989, pp. 1259-1262.

Jones, C. J. F. P. (2002). Geoguide 6: Guide to Reinforced Fill Structures and Slope Design. Geotechnical Engineering Office, Hong Kong, China.

Kaliakin, V. N., Dechasakulsom, M. \& Leshchinsky, D. (2000). Investigation of the isochrone concept for predicting relaxation of geogrids. Geosynthetics International, 7, No. 2, 79-99.

Lee, W. F. (2000). Internal Stability Analyses of Geosynthetic Reinforced Retaining Walls, PhD thesis, University of Washington, Seattle, Washington, USA.

McGown, A. \& Yogarajah, I. (1993). Choice of soil properties for limit state analysis of reinforced soil retaining structures. Proceedings of Retaining Structures, London,UK, pp. 529-540.

Mirmoradi, S. H. \& Ehrlich, M. (2015a). Modeling of the compaction-induced stress on reinforced soil walls. Geotextiles and Geomembranes, $\mathbf{4 3}$, No. 1, 82-88.

Mirmoradi, S. H. \& Ehrlich, M. (2015b). Numerical evaluation of the behavior of GRS walls with segmental block facing under working stress conditions. Journal of Geotechnical and Geoenvironmental Engineering, 141, No. 3, 04014109.

NCMA (National Concrete Masonry Association) (2002). Design Manual for Segmental Retaining Walls, NCMA, Herndon, Virginia, USA, $289 \mathrm{p}$

NGG (Nordic Geosynthetic Group) (2005). Nordic Guidelines for Reinforced Soils and Fills, NGG, Geothenburg, Sweden.

Plaxis B.V. (2014). Plaxis 2D Anniversary Edition (Version 2) [Computer Programme], Plaxis B.V., Delft, Netherlands, http://www.plaxis.nl (accessed 12/01/2015). 
Raja, J., Dixon, N., Frost, M., Fraser, I. \& Fowmes, G. (2012). Designing wih marginal fills: understanding and practice. Proceedings of 5 th European Geosynthetics Congress, Valencia, Spain, September 2012.

Rowe, R. K. \& Skinner, G. D. (2001). Numerical analysis of geosynthetic reinforced retaining wall constructed on a layered foundation. Geotextiles and Geomembranes, 19, No. 7, 387-412.

Schanz, T., Vermeer, P. A. \& Bonnier, P. G. (1999). The hardening soil model: formulation and verification. Proceedings of Beyond 2000 in Computational Geotechnics, Rotterdam, Netherlands, pp. 281-296.

Scotland, I., Dixon, N., Frost, M. \& Horgan, G. (2012). Serviceability limit state design in geogrid reinforced walls and slopes. Proceedings of 5th European Geosynthetics Congress, Valencia, Spain, September 2012.

Scotland, I., Dixon, N., Frost, M., Wackrow, R., Fowmes, G. \& Horgan, G. (2014). Measuring deformation performance of geogrid reinforced structures using a terrestrial laser scanner. Proceedings of 10th International Conference of Geosynthetics, Berlin, Germany, September 2014.

Stucki, M., Büsser, S., Itten, R., Frischknecht, R. \& Wallbaum, H. (2011). Comparative Life Cycle Assessment of Geosynthetics Versus Conventional Construction Materials, report for the European
Association of Geosynthetic Manufacturers, ESU-services $\mathrm{GmbH}$, Uster, Switzerland and ETH Zürich, Switzerland.

Teixeira, S. H. C., Bueno, B. S. \& Zornberg, J. G. (2007). Pullout resistance of individual longitudinal and transverse geogrid ribs. Journal of Geotechnical and GeoenvironmentalEengineering, 133, No. 1, 37-50.

Wang, Z., Jacobs, F. \& Ziegler, M. (2014). Visualization of load transfer behaviour between geogrid and sand using $\mathrm{PFC}^{2 \mathrm{D}}$. Geotextiles and Geomembranes, 42, No. 1, 83-90.

WRAP (Waste and Resource Action Programme) (2010). Sustainable Geosystems in Civil Engineering Applications, WRAP, Banbury, $\mathrm{UK}$.

Wu, J. T. H. (1994). CTI-UCD-1-94: Design and Construction of Low Cost Retaining Walls: The Next Generation in Technology, Colorado Transport Institute, Denver, Colorado, USA.

Wu, J. T. H., Pham, T. Q. \& Adams, M. T. (2013). FHWA-HRT-10-077. Composite Behaviour of Geosynthetic Reinforced Soil Mass, Federal Highways Administration, McLean, Virginia, USA, 211 p.

Yu, Y., Damians, I. P. \& Bathurst, R. J. (2015). Influence of choice of FLAC and PLAXIS interface models on reinforced soil-structure interactions. Computers and Geotechnics, 65, 164-174.

The Editor welcomes discussion on all papers published in Geosynthetics International. Please email your contribution to discussion@geosynthetics-international.com. 